Document downloaded from:

http://hdl.handle.net/10251/120140

This paper must be cited as:

García-Massó, X.; Ye Lin, Y.; Garcia-Casado, J.; Querol -Fuentes, F.; Gonzalez, L. (2019). Assessment of haemophilic arthropathy through balance analysis: a promising tool. Computer Methods in Biomechanics \& Biomedical Engineering. 22(4):418-425. https://doi.org/10.1080/10255842.2018.1561877

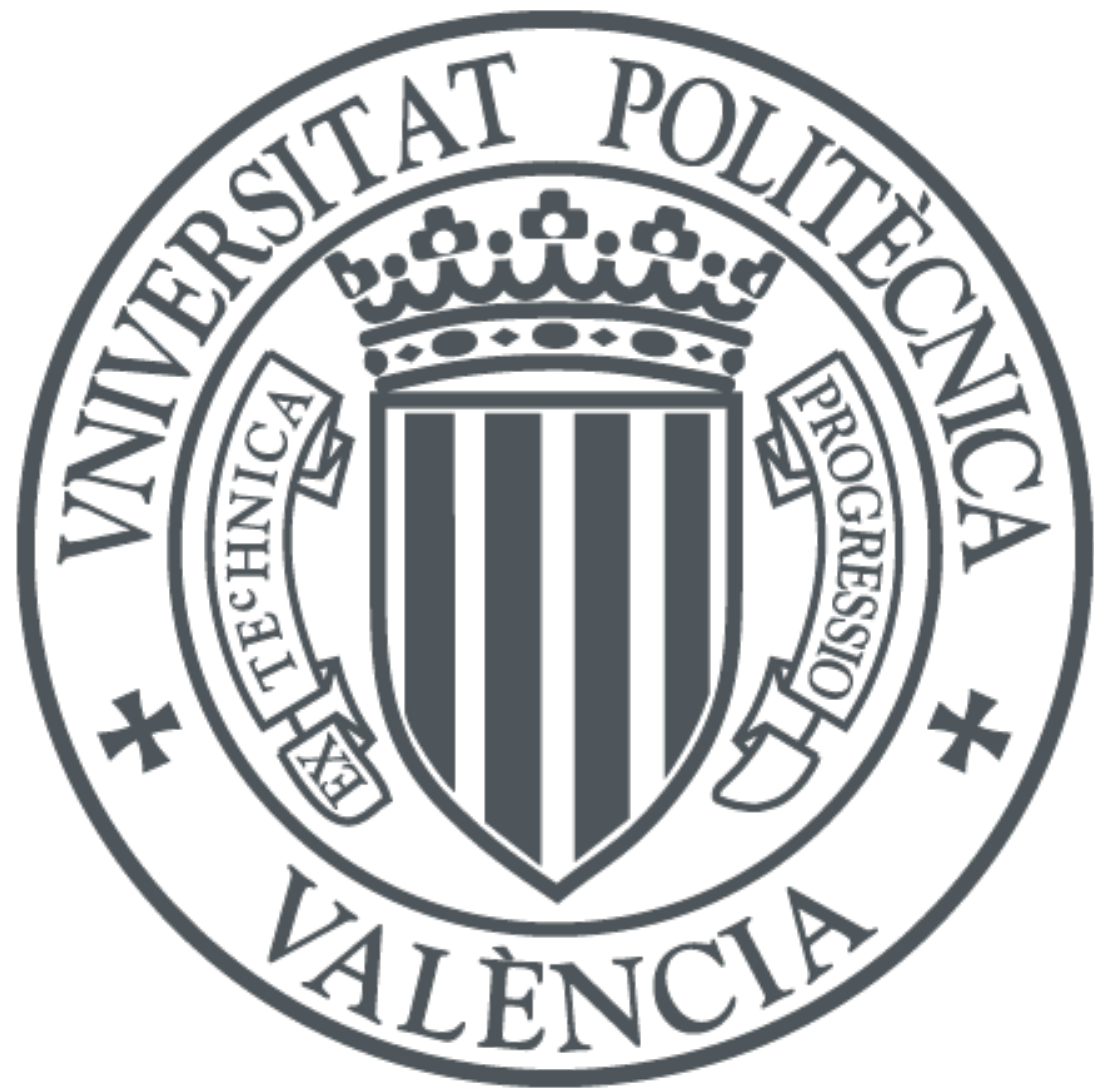

The final publication is available at

http://doi.org/10.1080/10255842.2018.1561877

Copyright Taylor \& Francis

Additional Information

This is an Author's Accepted Manuscript of an article published in Xavier García-Massó, Yiyao Ye-Lin, Javier Garcia-Casado, Felipe Querol \& Luis-Millan Gonzalez (2019) Assessment of haemophilic arthropathy through balance analysis: a promising tool, Computer Methods in Biomechanics and Biomedical Engineering, 22:4, 418-425, DOI: 10.1080/10255842.2018.1561877, available online at: http://doi.org/10.1080/10255842.2018.1561877. 


\section{Assessment of haemophilic arthropathy through balance analysis: a promising tool.}

Short title: Haemophilic arthropathy and balance

Xavier García-Massó ${ }^{1}$, Yiyao Ye-Lin ${ }^{2}$, Javier Garcia-Casado ${ }^{2}$, Felipe Querol ${ }^{3,4}$, LuisMillan Gonzalez ${ }^{5}$.

${ }^{1}$ Departamento de Didáctica de la Expresión Musical, Plástica y Corporal. Universidad de Valencia. Valencia, España.

${ }^{2}$ Centro de Investigación e Innovación en Bioingeniería (CI2B), Universitat Politècnica de València, Valencia, España

${ }^{3}$ Departamento de Fisioterapia, Universidad de Valencia. Valencia, España.

${ }^{4}$ Unidad de Trombosis y Hemostasia, Hospital Universitario La FE, Valencia, España.

${ }^{5}$ Departamento de Educación Física y Deportiva, Universidad de Valencia.

\section{Corresponding author:}

Dr. Luis-Millán González

Physical Education. University of Valencia

C/Gascó Oliag 3, Valencia 46010, Spain

Tel.: + 34/963/864 374

Fax: + 34/963/864 353

luis.m.gonzalez@uv.es 


\section{Abstract}

The purpose of this study was to develop a tool able to distinguish between subjects who have haemophilic arthropathy in lower limbs and those who do not by analyzing the centre of pressure displacement. The second objective was to assess the possible different responses of haemophiliacs and healthy subjects by creating a classifier that could distinguish between both groups. Fifty-four haemophilic patients (28 with and 26 without arthropathy) and 23 healthy subjects took part voluntarily in the study. A force plate was used to measure postural stability. A total of 276 centre of pressure displacement parameters were calculated under different conditions: unipedal/bipedal balance with eyes open/closed. These parameters were used to design a Quadratic Discriminant Analysis classifier. The arthropathy versus non-arthropathy classifier had an overall accuracy of $97.5 \%$ when only 10 features were used in its design. Similarly, the haemophiliac versus non-haemophiliac classifier had an overall accuracy of $97.2 \%$ when only 7 features were used. In conclusion, an objective haemophilic arthropathy in lower limbs evaluation system was developed by analyzing centre of pressure displacement signals. The haemophiliac vs. non-haemophiliac classifier designed was also able to corroborate the existing differences in postural control between haemophilic patients (with and without arthropathy) and healthy subjects.

Key Words: Centre of Pressures, Haemophilia, Arthropathy, Quadratic Discriminant Analysis. 


\section{Introduction}

Haemophilic arthropathy (HA) is the clinical manifestation of haemophilia with the highest morbidity (Hilgartner 2002). It is caused by repeated bleedings into joints that produces chronic proliferative synovitis and the destruction of articular cartilage (Raffini \& Manno 2007; Lafeber et al. 2008). The joints most frequently affected by HA are the knees, ankles and elbows, although it can also appear in other joints (Heim \& Horoszowski 1994; Molho et al. 2000; Plug et al. 2004; Aznar et al. 2009). It is accompanied by marked muscular atrophy of the affected joint, possibly due to its not being used (Tiktinsky et al. 2002), which in turn causes further weakness and instability. Such musculoskeletal problems mean that haemophilic patients suffer from physical debilitation and defective coordination (e.g. proprioception and balance) (Pietri et al. 1992; Falk et al. 2000; Hilberg et al. 2001; González et al. 2007; Gallach et al. 2008). Most specifically, it has been described an altered postural control in subjects with haemophilia regarding healthy adults (Gallach et al. 2008; Fearn et al. 2010). Moreover, the subject with HA showed lower postural control and stability than haemophilic subject without HA (Gallach et al. 2008). Recently, it has been found that patients with HA have less postural control irregularity and poor somatosensory system contributions that are compensated by more vestibular inputs (Cruz-Montecinos et al. 2017).

As early diagnosis of the condition is crucial in preserving the articular structure and function, as is monitoring its progress (Hacker et al. 2007), haematologists need to have tools available that enable them to evaluate the condition of patients' joints. This would allow them to initiate treatment and set the correct dosage of prophylaxis in patients at the first signs of HA (Pergantou et al. 2006; Khan et al. 2010), and refer them to the appropriate specialist. 
Up to the present time, various methods of assessing HA have been developed, which can be roughly divided into imaging score techniques and joint physical examination scales (Hacker et al. 2007; Doria 2010). Most scientific studies in this field have tried to improve the validity and reliability of arthropathy evaluation methods (Lundin et al. 2004; Pergantou et al. 2006; Silva et al. 2008; Doria 2010; Takedani et al. 2011). However, all the methods proposed to date have certain limitations; imaging techniques require specialist personnel and expensive equipment and the patients are often exposed to a range of x-ray dosages (Hacker et al. 2007), while physical examination scales also need to be administered by experts, are time-consuming and are generally incapable of detecting the early stages of the disease (Pergantou et al. 2006; Hacker et al. 2007). To date, no method has yet been devised of assessing arthropathy and its physical sequels that is independent of the observer, is easy to use, and can be applied by non-specialists.

We hypothesized that it would be possible to assess HA by means of the alterations caused to the patients' coordination capacities, especially in their sense of balance. The principal aim of our study was therefore to develop a tool that would be able to distinguish patients with arthropathy from those who do not by analyzing the centre of pressure $(\mathrm{CoP})$ displacement signals in a series of balance tests. In addition, since some research groups had found certain differences between the postural stability of patients with haemophilia (arthropathic and non-arthropathic) as compared to healthy subjects (Gallach et al. 2008; Fearn et al. 2010), a secondary objective was to construct another classifier able to corroborate the existence of such differences between both groups of subjects.

\section{Material and methods}

\section{Participants}


A total of 54 patients with haemophilia [Haemophilic Group (HG)] and 23 healthy subjects [Control Group (CG)] volunteered to participate in the study (Table 1). In the HG group, 28 subjects suffered from HA [haemophilic arthropathic group (HAG)] in either knees or ankles. Arthropathy was evaluated by means of the clinical score assessment of the Orthopaedic Advisory Committee of the World Federation of Haemophilia (Pipe \& Valentino 2007), on a scale of 0 (absence of arthropathy) to 15 (severe arthropathy). Those who scored a total higher than 6 (i.e. total score of both knees and both ankles) were considered as arthropathic patients. The other 26 patients did not suffer from HA [haemophilic non-arthropathic group (HNAG)]. Absence of arthropathy was defined as a total score of 6 or less for all four joints. All the patients were able to walk and maintain bipedal and unipedal stance effortlessly. Table 2 gives the characteristics of the haemophilic patients.

Table 1. Subject's age and anthropometric characteristics.

\begin{tabular}{ccc}
\hline & CG $(\mathbf{n}=\mathbf{2 3})$ & HG $(\mathbf{n = 5 4 )}$ \\
\hline Age (years) & $32.39(2.68)$ & $30.44(1.79)$ \\
Height $(\mathrm{cm})$ & $175.52(1.06)$ & $170.18(1.36)$ \\
Weight $(\mathrm{kg})$ & $78.00(2.23)$ & $69.18(1.79)$ \\
\hline
\end{tabular}

Data are expressed as mean (SEM). CG= Control Group; HG= Haemophilic Group. 
Table 2. Haemophilic Group characteristics.

\begin{tabular}{lcc}
\hline & HAG $(\mathbf{n = 2 8})$ & HNAG $(\mathbf{n = 2 6})$ \\
\hline Age (years) & $34.07(2.53)^{*}$ & $26.54(2.34)$ \\
Height $(\mathrm{cm})$ & $168.71(1.67)$ & $171.77(2.16)$ \\
Weight $(\mathrm{kg})$ & $67.79(2.69)$ & $70.69(2.36)$ \\
& & 6 \\
Illness Severity (n) & 2 & 10 \\
Mild & 6 & 10 \\
Moderate & 20 & \\
\hline Severe & &
\end{tabular}

Data are expressed as mean (SEM). HAG= Haemophilic Arthropatic Group; HNAG= Haemophilic Non Arthropatic Group.

- Indicate significant differences regarding HNAG $(\mathrm{p}<0.05)$ using TStudent test for independent samples.

Additionally, to obtain and test the classifiers, a mixed group was formed of the persons from the control and haemophilic non-arthropathic patients: non-arthopathic group (NAG). Figure 1 contains a diagram of the composition of the various groups.

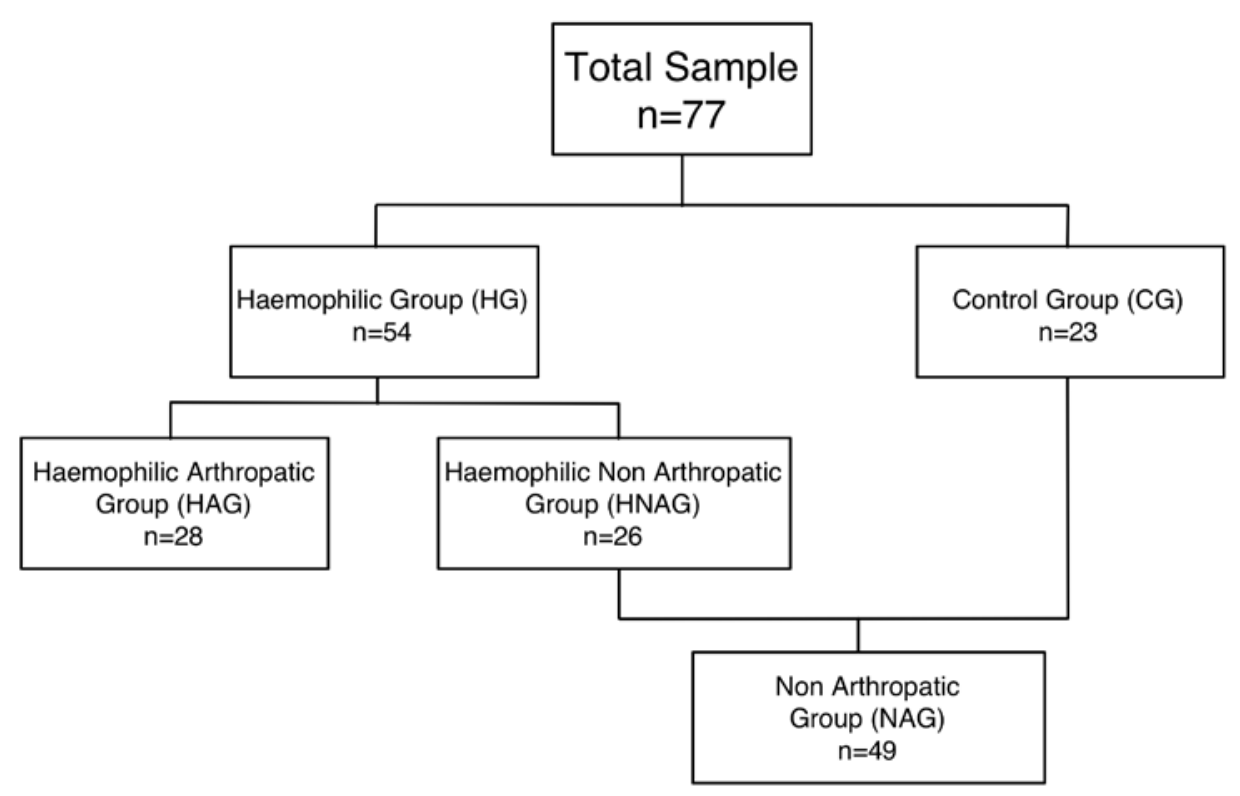

Figure 1. Flowchart of the subjects allocated to each group

The members of the CG were considered to be sedentary, i.e. individuals that did not take part in any form of habitual physical exercise (i.e. programmed, structured and 
repetitive movements carried out to improve or maintain one or more of the elements of physical fitness). None of these subjects suffered from neurological, musculoskeletal (including arthropathy), visual or vestibular pathologies that could have affected their balance. The physician in the research team completed a medical history of these participants to discard any such pathologies. The members of the CG were selected in such a way as to represent similar weight, height and age characteristics as the group of patients, so that there were no significant differences between both groups ( $p>0.05)$ (see Table 1).

All the participants signed an informed consent form before the tests. The protocols used in the study were approved by an ethical committee and met all the requirements set out in the 1975 Declaration of Helsinki and in the later revisions.

\section{Static posturography}

A force plate was used to measure postural stability (Kistler 9253B11; Kistler Instrument AG, Winterthur, Switzerland). The platform consisted of a 100 x 600 x 400 mm plate with four quartz sensors. The platform was placed on a stable floor surface to avoid distortion and noise in the signal. A point of reference (5 $\mathrm{cm}$ in diameter) was placed $2 \mathrm{~m}$ in front of the subjects at eye level. All the subjects were informed of the importance of maintaining the posture and standing as still as possible during the postural tasks. One 30 s test was carried out under each of the following conditions: i) bipedal stance with eyes open (BEO), ii) bipedal stance with eyes closed (BEC), iii) Unipedal stance on the dominant foot (UDEO), and iv) Unipedal stance on nondominant foot (UNDEO). In all the trials, the subjects stood barefoot with their arms relaxed by their sides with the same foot placement: i) in bipedal trials, heels separated by the width of the shoulders and toes pointing forward, ii) in unipedal trials the supporting foot in the middle of the platform and pointing forward while the other leg 
was flexed $90^{\circ}$. An experimenter visually checked the correct posture during the trials. The dominant leg was determined by "kicking preference”.

The signals from the individual tests were recorded at a frequency of $200 \mathrm{~Hz}$. The data representing the forces exerted on the platform along three axes $(\mathrm{x}, \mathrm{y}, \mathrm{z})$ were saved on a hard disk for subsequent analysis.

\section{Data analysis}

The ground reaction forces were processed to obtain the CoP displacement data in both the mediolateral and anteroposterior directions, using Bioware 3.4 analysis software (Kistler Instrument AG, Winterthur, Switzerland). This software uses standard computations of the $\mathrm{CoP}$ as recommended by the International Society of Biomechanics.

Then Matlab 2008a (Mathworks Inc, Natick, USA) was used to perform data analysis. CoP displacement data were low-pass filtered with a Butterworth $10 \mathrm{~Hz}$ cut-off frequency filter. Linear and non-linear analysis techniques were applied in the anteroposterior (AP), mediolateral (ML) and resultant-distance (RD) directions (Eq. 1). Figure 2 shows the recording protocol and examples of the AP, ML and RD signals from a haemophilic patient.

$$
R D_{i}=\sqrt{A P_{i}^{2}+M L_{i}^{2}} \quad \text { Eq. } 1
$$

The linear analysis included 27 variables in the temporal and frequency domains for all possible directions (i.e. AP, ML and RD) that had been used in previous studies by Prieto et al. (Prieto et al. 1996), Cabeza-Ruiz et al. (Cabeza-Ruiz et al. 2011) and Amoud et al. (Amoud et al. 2007). Considering the four balance exercises performed by each subject, a total of 276 parameters for each register were calculated to characterise 
the postural control of the individual subjects. A detailed list of the variables included in the study can be seen in Tables 1s, 2s and 3s in Supporting Information.

Since data distributions of these variables were not normal Wilcoxon Rank sum was used to test statistical significance between HAG and NAG groups. Since age presented significant statistical differences between HAG and HNAG, statistical dependency of parameters with age was tested with chi-square test of independence, and those with $\mathrm{p}<0.05$ were excluded from the analysis.
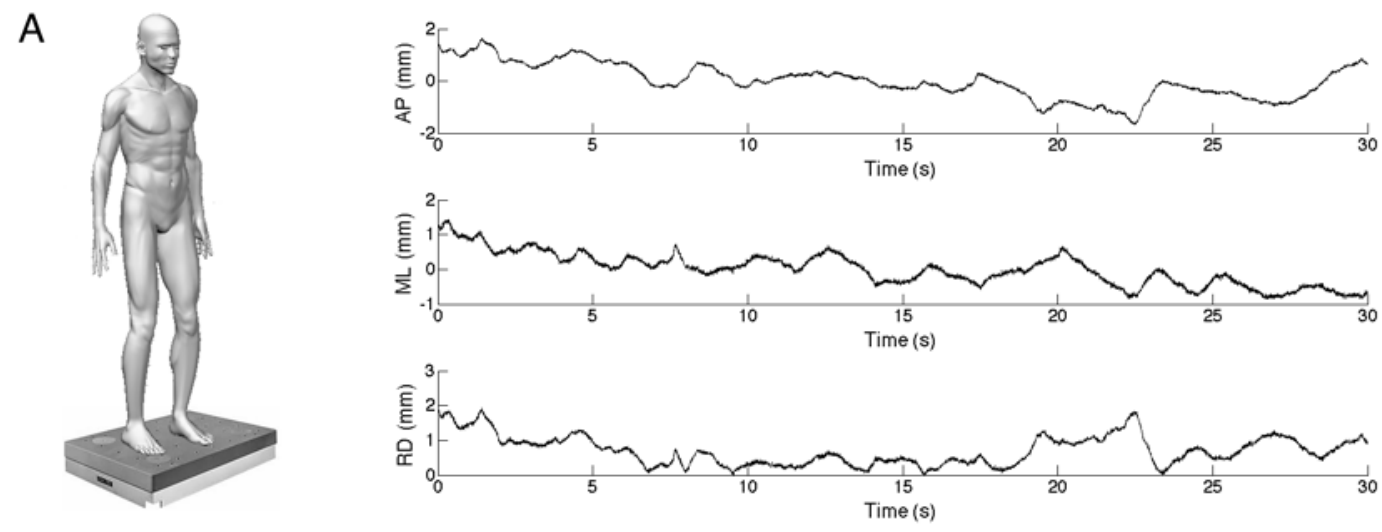

B
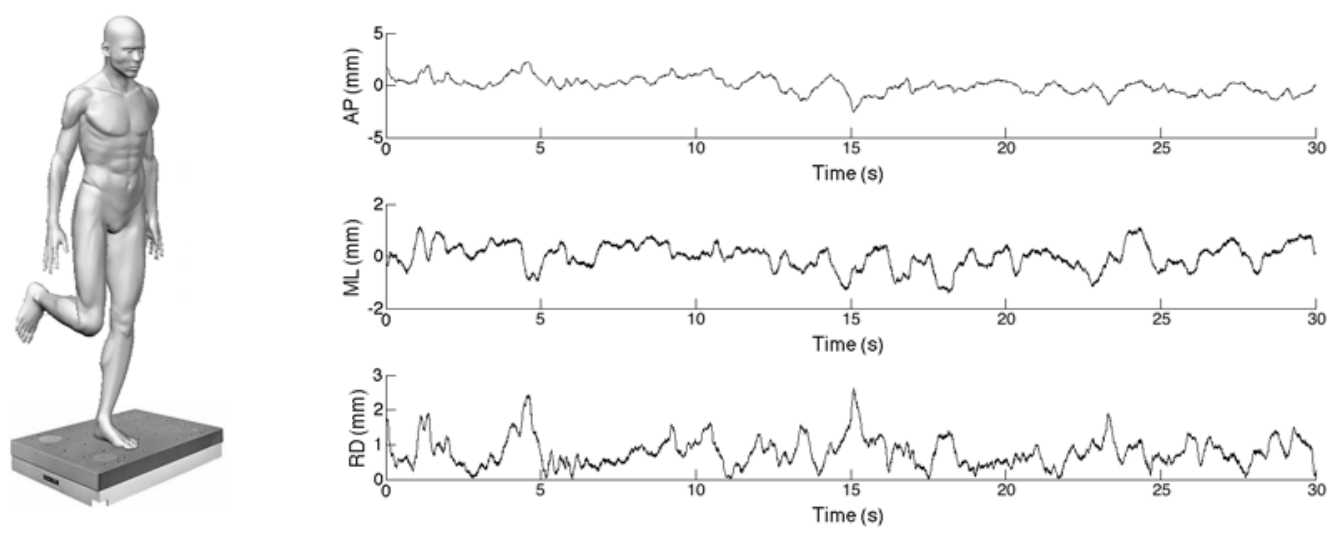

Figure 2. Experimental setup for balance measurements and an example of antero-posterior (AP), medio-lateral $(M L)$ and resultant distance $(R D)$ signals during bipedal with eyes open $(A)$ and monopedal with dominant leg (B).

The data collected was used to design a Quadratic Discriminant Analysis (QDA) classifier which is a statistical classification method to separate measurements of two or more classes of objects by a quadric surface where there is no assumption that the covariance of each class is identical (Hastie et al. 2009). Two independent classifiers 
were used in this study: arthropathy (HAG: 28 subjects of the arthropathic group) vs. no-arthropathy (NAG: 26 patients from the non-arthropathic group and 23 healthy subjects from the control group); and haemophilic patients (HG: 54 patients from the haemophilic group) vs. non-haemophilic (CG: 23 patients from the control group). Since the database involved in this study was relatively small, a 5-fold cross-validation with no overlap was used, i.e. $80 \%$ of each data group was selected randomly for training and the remaining $20 \%$ was used for testing. In order to test the overall classification rate, a classifier for each fold of training data was implemented and then the $20 \%$ testing data of the corresponding fold was used for its evaluation. In order to reduce the classification rate variability due to randomness, cross-validation was performed 50 times.

So as to assess the information that can be derived from each of the stance tests, four classifiers were implemented using only the 66 parameters derived from each BEO, BEC, UDEO, UNDEO exercise, respectively. Three classifiers were implemented combining the information derived from the BEO and BEC exercises (BEO $\cup B E C$ ), from UDEO and UNDEO (UDEOUUNDEO), and combining all four exercises (BEO $\cup B E C \cup U D E O \cup U N D E O)$. A sequential forward feature selection algorithm was used to obtain the optimal feature subset, which maximizes the QDA classifier's predictive accuracy with the minimum number of features. All parameters were considered 'candidates' to be included in the model regardless of results of statistical tests, since they could provide complementary information that could enrich the classifier performance.

Finally, for the classifier that yielded best global (train+test group) accuracy (Eq. 2), the following parameters were calculated to evaluate more precisely its prediction 
performance: sensitivity (Eq. 3), specificity (Eq. 4), positive predictive value (Eq. 5) and negative predictive value (Eq. 6).

$$
\begin{array}{rrr}
\text { Accuracy } & =\frac{T P+T N}{N} \cdot 100(\%) & \text { Eq.2 } \\
\mathrm{SE} & =\frac{T P}{T P+F N}-100(\%) & \text { Eq.3 } \\
\mathrm{SP} & =\frac{T N}{T N+F P}-100(\%) & \text { Eq.4 } \\
\mathrm{PPV} & =\frac{T P}{T P+F P} \cdot 100(\%) & \text { Eq.5 } \\
\mathrm{NPV} & =\frac{T N}{T N+F N}-100(\%) & \text { Eq.6 }
\end{array}
$$

Where $\mathrm{N}$ is total number of patients evaluated; TP is the number of true positives; TN is the number of true negatives, FN is the number of false negatives and FP is the number of false positives, SE is sensitivity, SP is specificity, PPV is the positive prognostic value and NPV negative prognostic value.

\section{Results}

The average accuracy (50 iterations) of the classifier with the parameters from the 4 balance exercises (ALL) is shown in Figure 3. The classifiers that only considered parameters from each single exercise and the classifiers that combined bipedal or unipedal exercises [two bipedal (BEO $\cup$ BEC) and two unipedal exercises (UDEO $\cup$ UNDEO)] were calculated to determine the possibility of reducing the number of exercises required in the recording protocol. The results are also shown in Figure 3 for comparison. As expected, the best accuracy is obtained when considering data from ALL exercises in all groups. The overall accuracy for the whole database was $97.5 \%$ for 
ALL, followed by BEO $\cup$ BEC, with 95.8\%. This means that a simplified protocol with only bipedal measurements could achieve an accuracy of over 95\%. However, considering the results for the Test database, BEO $\cup$ BEC yields an accuracy of $84.9 \%$ vs $90.7 \%$ for ALL. This indicates the BEO $\cup B E C$ classifier's poorer generalization capacity, which should be taken into account. The rest of the classifiers yielded lower overall accuracy values (from $83.4 \%$ to $93.4 \%$ ) especially in the Test group. The best combination of features for each classifier with different input features are detailed in Table 4s in Supporting Information. It can be seen that the number of features is small (10 for ALL and from 8 to 12 for the rest). In general, the parameters from all the domains (temporal, spectral and non-linear) are used in all cases with no relevant trends.

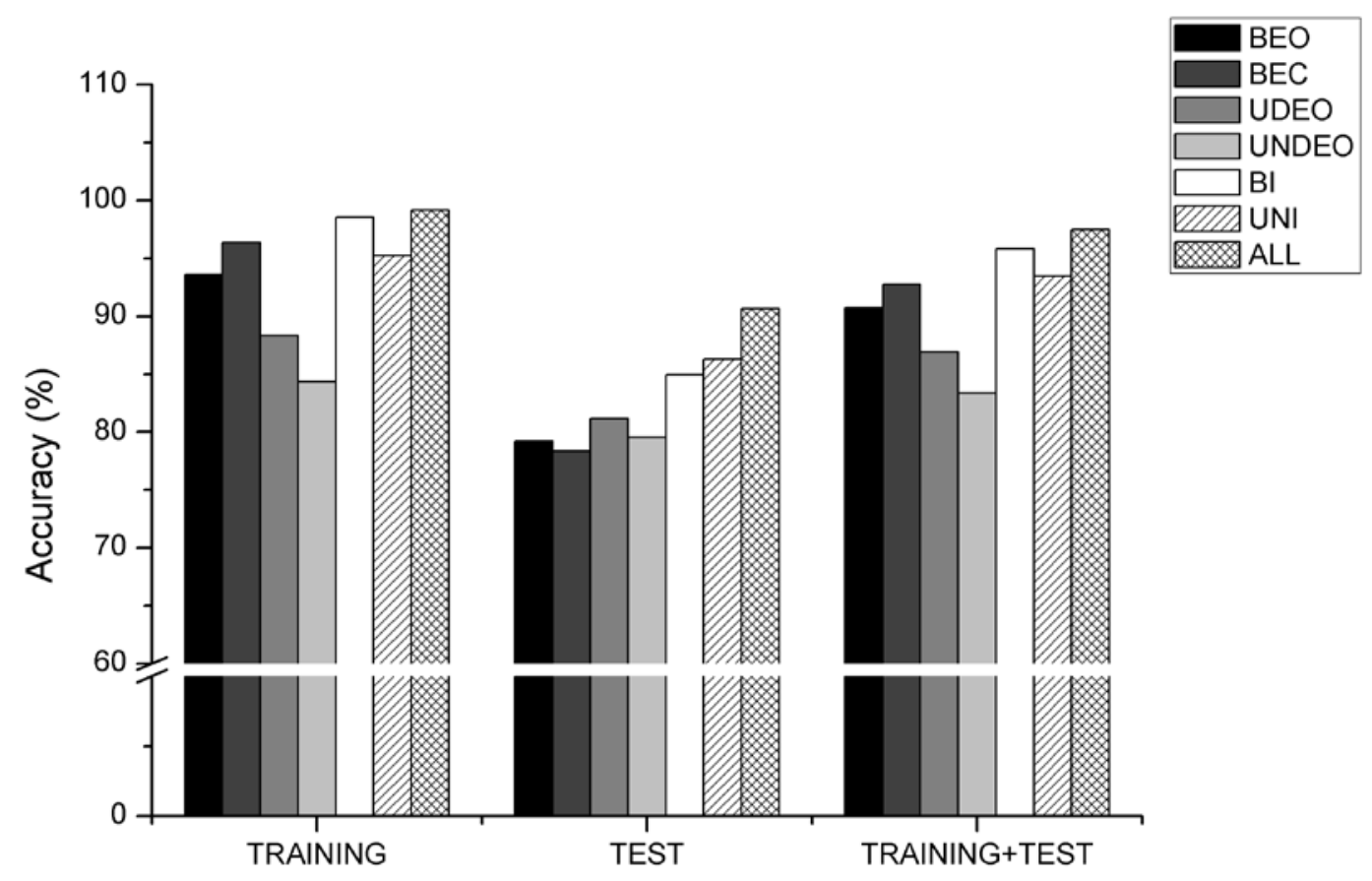

Figure 3. Accuracy of the proposed classifiers haemophilic arthropathy vs non-arthropathy for the training, test and trainingptest groups. $\mathrm{BEO}=$ bipedal with eyes open; $\mathrm{BEC}=$ bipedal with eyes closed; UDEO=unipedal with dominant leg and eyes open; UNDEO=unipedal with non-dominant leg and eyes open; $\mathrm{BI}=$ bipedal with eyes open and bipedal with eyes closed; UNI=unipedal with dominant leg and unipedal with non-dominant leg and eyes open; $A L L=$ the four balance tests

Table 3 gives the characteristic parameters of the performance of the best classifier (features from all exercises). It can be appreciated that the lowest value is obtained for 
sensitivity, especially in the Test group. This seems to imply that some of the 'true' arthropathic subjects could have been incorrectly classified due to the unbalanced database and the criteria of maximizing the accuracy of the classifier. Modified versions of the classifier could be developed to specifically optimize sensitivity. The proposed classifier performed well in terms of positive prognostic value and specificity parameters, with scores of over 99\% for the entire database.

Table 3. Characteristic parameters of the performance of the best classifier [ALL]: Haemophilic Arthropatic Group (HAG) versus Non Artropatic Group (NAG).

\begin{tabular}{llcrrrc}
\hline$N$ & & Accuracy (\%) & SE (\%) & SP(\%) & PPV (\%) & NPV (\%) \\
\hline 308 & Training & 99.2 & 97.9 & 99.9 & 99.9 & 98.8 \\
77 & Test & 90.7 & 76.8 & 98.6 & 96.9 & 88.1 \\
385 & Training+test & 97.5 & 93.6 & 99.7 & 99.4 & 96.5
\end{tabular}

$\mathrm{SE}=$ sensitivity; $\mathrm{SP}=$ specificity; $\mathrm{PPV}=$ positive prognostic value; $\mathrm{NPV}=$ negative prognostic value.

The prediction capability parameters of the haemophilic vs non-haemophilic classifier are shown in Table 4. This classifier considers parameters from the four exercises, and with only 7 parameters yields an overall accuracy of $97.2 \%$, supporting the hypothesis that there are differences between the postural stability of haemophiliacs (arthropathic and non-arthropathic) and healthy subjects. Values greater than $96 \%$ were obtained for overall sensitivity, specificity and the positive prognostic value.

Table 4. Characteristic parameters of the performance of the best classifier [ALL]: Haemophilic Group (HG) versus Control Group (CG).

\begin{tabular}{llccccc}
\hline$N$ & & Accuracy (\%) & SE (\%) & SP (\%) & PPV (\%) & NPV (\%) \\
\hline 308 & Training & 97.9 & 97.0 & 100 & 100 & 93.4 \\
77 & Test & 94.6 & 96.0 & 91.4 & 96.3 & 90.6 \\
385 & Training+test & 97.2 & 96.8 & 98.3 & 99.2 & 92.8 \\
\hline
\end{tabular}


$\mathrm{SE}=$ sensitivity; $\mathrm{SP}=$ specificity; $\mathrm{PPV}=$ positive prognostic value; $\mathrm{NPV}=$ negative prognostic value.

\section{Discussion}

The results obtained show that HA in the lower limbs can be detected by measuring static balance, which verifies the hypothesis postulated in this study. This implies an important advance on the methods used to date to detect and evaluate HA, since for the first time a method can be applied totally independent of a clinical observer/expert.

Maintaining postural control depends on the proper functioning of different systems and apparatus in the human body, and many pathologies can have a deleterious effect on static balance (e.g. Parkinson’s Disease, Down’s Syndrome, musculoskeletal lesions, etc.) (Mitchell et al. 1995; Cabeza-Ruiz et al. 2011). As regards HA and osteoarthritis (which has a different cause but is similar as regards its course), the existing evidence shows that the most severe cases of these diseases have the worst postural control (Masui et al. 2006; Gallach et al. 2008; Fearn et al. 2010; Kurz et al. 2011; De Souza et al. 2012; Souza et al. 2013).

In fact, the differences in the postural control of haemophilic patients gave rise to the present study. The methods used up to the present time to evaluate arthropathy are directly dependent on the observer or person who carries out the assessment, in other words, the imaging techniques and clinical evaluations of HA have a certain degree of subjectivity and must be carried out by trained personnel (Pergantou et al. 2006; Hacker et al. 2007). This is precisely why estimating the effects of HA on the musculoskeletal system, especially on postural control, by an objective means is so important. The present study has shown that HA can be detected by measuring the patient's static balance. Even though numerous parameters can be extracted from CoP displacement 
data, at an additional computational cost, we observed that a combination of a few variables (7 for the Haemophiliacs vs Non-Haemophiliacs Classifier and 10 for the Arthropathy vs Non-Arthropathy Classifier) provide the information necessary to implement the classifier.

This new method of classifying patients with HA implies a big advance on the methods used to date. Firstly, due to its objective system of detecting HA, it is the only method completely independent of a specialist operator for its application. This means the results obtained in assessing haemophilic patients will be consistent, regardless of whoever carries out the task. Since these patients are habitually treated by haematologists and not by joint specialists (i.e. rheumatologists and rehabilitation experts), the proposed system could become a fundamental tool in clinics specializing in this pathology. In addition, it has no negative effects on patients, such as being exposed to x-rays. Also, the implemented classifier is easily integrated into balance-measuring devices and is thus easy to use in a clinical environment. A further advantage is that digital signal processing can now be measured by a large number of balance assessment systems (e.g. photogrammetry, video, accelerometry, force plates) and different variables can be obtained that contain information on postural control and its related mechanisms. In our case, we analysed the displacements of $\mathrm{CoP}$ acquired by a force plate, since it is one of the simplest, cheapest and reliable methods. All the measurements required can be obtained in a very short time, which, together with its other advantages, confer great utility and versatility on the proposed HA assessment system.

As regards this aspect, the best results in diagnosing HA were obtained from four simple balance tests (BEO, BEC, UDEO and UNDEO), which can be performed in a period of five to ten minutes. We studied the possibility of reducing the number of tests 
and discovered that with only bipedal stance tests an accuracy of $>95 \%$ could be obtained, although with a lower capacity to generalize than when using four tests. Since the performance of all the tests can be done in less than 10 minutes, it is recommended to perform the four of them.

However, despite the advances implied in the results obtained, it will be necessary to carry on this line of research in order to improve the tool and reduce its cost. One of the limitations of the present study was that only one clinical HA assessment was used to classify patients as arthropathic or non-arthropathic. Future studies will test our system using image-based arthropathy assessment as the gold standard.

A larger sample would have made it possible to make wider generalizations of the results for the different load-bearing joints and/or different degrees of arthropathy. Finally, if the system were to be implemented with two force plates, bearing asymmetries could be detected and included as input information in the classification system, although this would increase the system's complexity and cost. These limitations will lead to future research in order to increase the system's accuracy as far as possible.

We therefore believe that the diffusion of our results among the scientific community is important in order to encourage other research groups to cooperate in obtaining larger data bases. Our group is at present engaged in extending the available data and reducing the cost of the measuring devices in order to improve the system and ultimately to design a simple, objective, effective and inexpensive HA diagnostic software. It should be noted that at this stage, the present system is not meant to replace the typical assessment of arthropathy by a specialist. However, it could make a greater impact in areas without specialised haemophilia or rheumatology units. Apart from the results obtained, the method proposed in this paper could be applied to other populations with 
similar problems, for example to arthropathy patients. It should also be understood that the second classifier developed to separate haemophilic from non-haemophilic subjects, does not aim to replace the battery of examinations traditionally used for this purpose. It should thus be considered as an additional, objective and low-cost test, to help practitioners to interpret of the whole data set and provide information about the possible incidence of hemophilic arthropathy in its early stages.

In conclusion, the results show that postural control of subject with haemophilic arthropathy is different to that of healthy subjects and that haemophilic arthropathy could be diagnosed by means of balance tests. By analyzing CoP displacements, we succeeded in developing an HA assessment system with a classification precision of 97.5\%. In addition, we also obtained a classifier with an accuracy of $97.2 \%$ able to distinguish between haemophiliacs and healthy subjects. Even though this at present may not have any practical applications, it can be considered as a confirmation of the patients' reduced postural control, whether or not they suffer from HA, as compared to non-haemophilic subjects.

\section{Acknowledgements}

The authors have no competing interests. 


\section{References}

Amoud H, Abadi M, Hewson DJ, Michel-Pellegrino V, Doussot M, Duchêne J. 2007. Fractal time series analysis of postural stability in elderly and control subjects. J Neuroeng Rehabil. 4:12.

Aznar JA, Abad-Franch L, Cortina VR, Marco P. 2009. The national registry of haemophilia A and B in Spain: results from a census of patients. Haemophilia. 15:13271330.

Cabeza-Ruiz R, García-Massó X, Centeno-Prada RA, Beas-Jiménez JD, Colado JC, González L-M. 2011. Time and frequency analysis of the static balance in young adults with Down syndrome. Gait Posture. 33:23-28.

Cruz-Montecinos C, De la Fuente C, Rivera-Lillo G, Morales-Castillo S, Soto-Arellano V, Querol F, Pérez-Alenda S. 2017. Sensory strategies of postural sway during quiet stance in patients with haemophilic arthropathy. Haemophilia. 23: e419-e426.

De Souza FMB, Pereira RP, Minuque NP, Do Carmo CM, De Mello MHM, Villaça P, Tanaka C. 2012. Postural adjustment after an unexpected perturbation in children with haemophilia. Haemophilia. 18:e311-315.

Doria AS. 2010. State-of-the-art imaging techniques for the evaluation of haemophilic arthropathy: present and future. Haemophilia. 16 Suppl 5:107-114.

Falk B, Portal S, Tiktinsky R, Weinstein Y, Constantini N, Martinowitz U. 2000. Anaerobic power and muscle strength in young hemophilia patients. Med Sci Sports Exerc. 32:52-57.

Fearn M, Hill K, Williams S, Mudge L, Walsh C, McCarthy P, Walsh M, Street A. 2010. Balance dysfunction in adults with haemophilia. Haemophilia. 16:606-614.

Gallach JE, Querol F, González LM, Pardo A, Aznar JA. 2008. Posturographic analysis of balance control in patients with haemophilic arthropathy. Haemophilia. 14:329-335.

González L-M, Querol F, Gallach JE, Gomis M, Aznar VA. 2007. Force fluctuations during the maximum isometric voluntary contraction of the quadriceps femoris in haemophilic patients. Haemophilia. 13:65-70.

Hacker MR, Funk SM, Manco-Johnson MJ. 2007. The Colorado haemophilia paediatric joint physical examination scale: normal values and interrater reliability. Haemophilia. 13:71-78.

Hastie T, Tibshirani R, Friedman J. 2009. The elements of statistical learning. Data mining, inference, and prediction. New York: Springer.

Heim M, Horoszowski H. 1994. A 26-year-old HIV-positive hemophiliac with knee pain. Orthop Rev. 23:339-343. 
Hilberg T, Herbsleb M, Gabriel HH, Jeschke D, Schramm W. 2001. Proprioception and isometric muscular strength in haemophilic subjects. Haemophilia. 7:582-588.

Hilgartner MW. 2002. Current treatment of hemophilic arthropathy. Curr Opin Pediatr. 14:46-49.

Khan U, Bogue C, Ungar WJ, Hilliard P, Carcao M, Moineddin R, Doria AS. 2010. Cost-effectiveness analysis of different imaging strategies for diagnosis of haemophilic arthropathy. Haemophilia. 16:322-332.

Kurz E, Herbsleb M, Anders C, Puta C, Vollandt R, Czepa D, Ziezio R, Scholle H-C, Hilberg T. 2011. SEMG activation patterns of thigh muscles during upright standing in haemophilic patients. Haemophilia. 17:669-675.

Lafeber FPJG, Miossec P, Valentino LA. 2008. Physiopathology of haemophilic arthropathy. Haemophilia. 14 Suppl 4:3-9.

Lundin B, Pettersson H, Ljung R. 2004. A new magnetic resonance imaging scoring method for assessment of haemophilic arthropathy. Haemophilia. 10:383-389.

Masui T, Hasegawa Y, Yamaguchi J, Kanoh T, Ishiguro N, Suzuki S. 2006. Increasing postural sway in rural-community-dwelling elderly persons with knee osteoarthritis. J Orthop Sci. 11:353-358.

Mitchell SL, Collins JJ, De Luca CJ, Burrows A, Lipsitz LA. 1995. Open-loop and closed-loop postural control mechanisms in Parkinson's disease: increased mediolateral activity during quiet standing. Neurosci Lett. 197:133-136.

Molho P, Rolland N, Lebrun T, Dirat G, Courpied JP, Croughs T, Duprat I, Sultan Y. 2000. Epidemiological survey of the orthopaedic status of severe haemophilia A and B patients in France. The French Study Group. secretariat.haemophiles@cch.ap-hopparis.fr. Haemophilia. 6:23-32.

Pergantou H, Matsinos G, Papadopoulos A, Platokouki H, Aronis S. 2006. Comparative study of validity of clinical, $\mathrm{X}$-ray and magnetic resonance imaging scores in evaluation and management of haemophilic arthropathy in children. Haemophilia. 12:241-247.

Pietri MM, Frontera WR, Pratts IS, Súarez EL. 1992. Skeletal muscle function in patients with hemophilia A and unilateral hemarthrosis of the knee. Arch Phys Med Rehabil. 73:22-28.

Pipe SW, Valentino LA. 2007. Optimizing outcomes for patients with severe haemophilia A. Haemophilia. 13:1-16.

Plug I, van der Bom JG, Peters M, Mauser-Bunschoten EP, de Goede-Bolder A, Heijnen L, Smit C, Zwart-van Rijkom JEF, Willemse J, Rosendaal FR. 2004. Thirty years of hemophilia treatment in the Netherlands, 1972-2001. Blood. 104:3494-3500.

Prieto TE, Myklebust JB, Hoffmann RG, Lovett EG, Myklebust BM. 1996. Measures of postural steadiness: differences between healthy young and elderly adults. IEEE Trans Biomed Eng. 43:956-966. 
Raffini L, Manno C. 2007. Modern management of haemophilic arthropathy. $\mathrm{Br} \mathrm{J}$ Haematol. 136:777-787.

Silva M, Luck JV, Quon D, Young CR, Chin DM, Ebramzadeh E, Fong Y-J. 2008. Inter- and intra-observer reliability of radiographic scores commonly used for the evaluation of haemophilic arthropathy. Haemophilia. 14:504-512.

Souza FMB, McLaughlin P, Pereira RP, Minuque NP, Mello MHM, Siqueira C, Villaça P, Tanaka C. 2013. The effects of repetitive haemarthrosis on postural balance in children with haemophilia. Haemophilia. 19:e212-217.

Takedani H, Fujii T, Kobayashi Y, Haga N, Tatsunami S, Fujii T. 2011. Inter-observer reliability of three different radiographic scores for adult haemophilia. Haemophilia. 17:134-138.

Tiktinsky R, Falk B, Heim M, Martinovitz U. 2002. The effect of resistance training on the frequency of bleeding in haemophilia patients: a pilot study. Haemophilia. 8:22-27. 


\section{Figure Captions}

Fig 1. Flowchart of the subjects allocated to each group.

Fig 2. Experimental setup for balance measurements and an example of antero-posterior (AP), medio-lateral (ML) and resultant distance (RD) signals during bipedal with eyes open (A) and monopedal with dominant leg (B).

Fig 3. Accuracy of the proposed classifiers haemophilic arthropathy vs non-arthropathy for the training, test and training+test groups. $\mathrm{BEO}=$ bipedal with eyes open; $\mathrm{BEC}=$ bipedal with eyes closed; UDEO = unipedal with dominant leg and eyes open; UNDEO = unipedal with non-dominant leg and eyes open; BI = bipedal with eyes open and bipedal with eyes closed; UNI = unipedal with dominant leg and unipedal with nondominant leg and eyes open; ALL = the four balance tests. 
Table 2s. Descriptive statistics of the time domain variables.

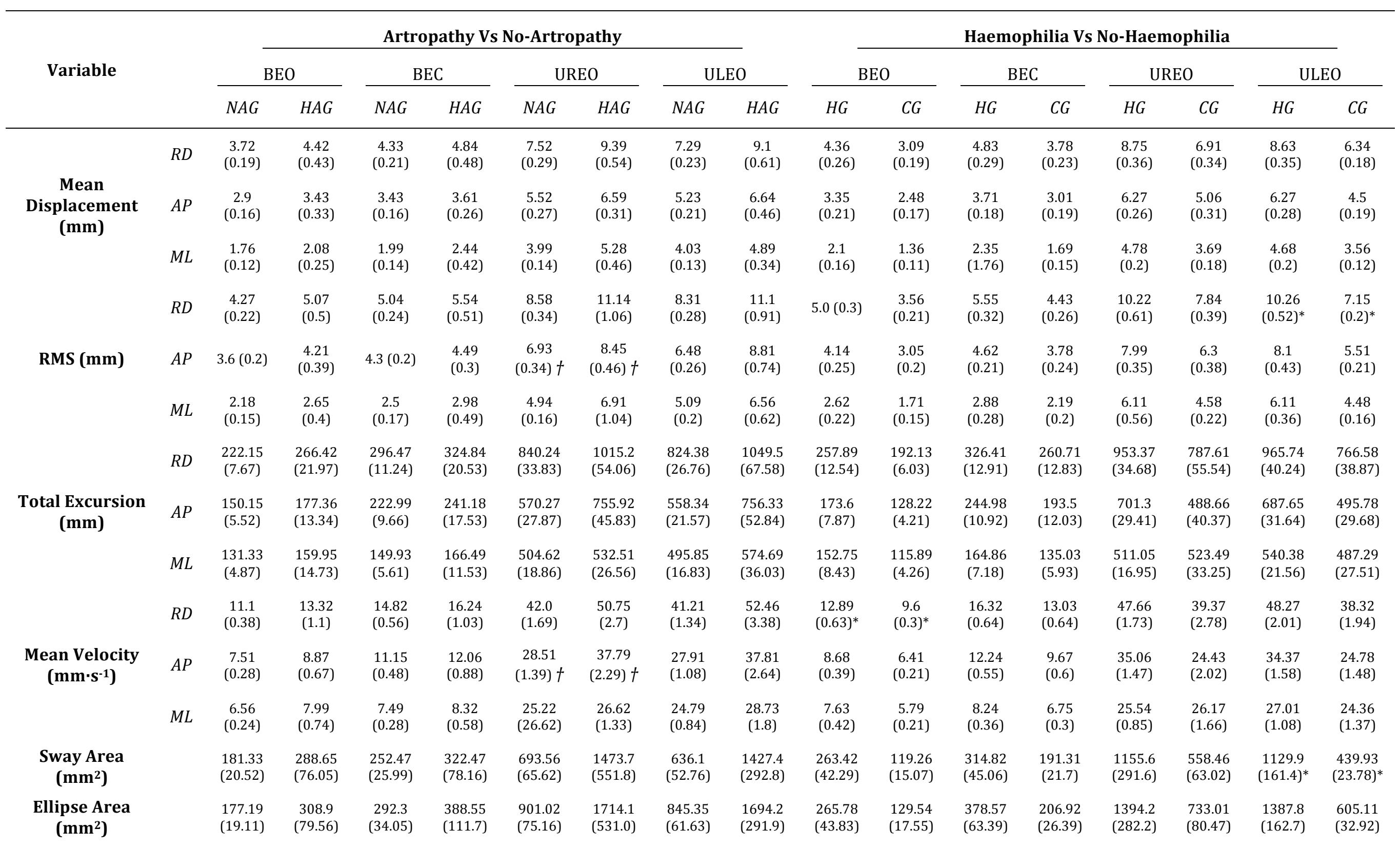




\begin{tabular}{|c|c|c|c|c|c|c|c|c|c|c|c|c|c|c|c|c|c|}
\hline & $R D$ & $\begin{array}{c}15.1 \\
(0.81)\end{array}$ & $\begin{array}{l}18.88 \\
(2.24)\end{array}$ & $\begin{array}{l}20.58 \\
(1.02)\end{array}$ & $\begin{array}{c}21.0 \\
(1.38)\end{array}$ & $\begin{array}{l}35.14 \\
(1.88)\end{array}$ & $\begin{array}{c}45.98 \\
(4.0)\end{array}$ & $\begin{array}{l}33.9 \\
(1.4)\end{array}$ & $\begin{array}{l}49.59 \\
(4.92)\end{array}$ & $\begin{array}{l}17.96 \\
(1.29)\end{array}$ & $\begin{array}{l}12.99 \\
(0.85)\end{array}$ & $\begin{array}{l}21.84 \\
(1.02)\end{array}$ & $\begin{array}{c}18.12 \\
(1.2)\end{array}$ & $\begin{array}{l}42.69 \\
(2.43)\end{array}$ & $\begin{array}{l}30.63 \\
(2.52)\end{array}$ & $\begin{array}{l}44.63 \\
(2.78)\end{array}$ & $\begin{array}{c}27.8 \\
(1.19)\end{array}$ \\
\hline \multirow[t]{2}{*}{$\begin{array}{l}\text { Range } \\
\text { (mm) }\end{array}$} & $A P$ & $\begin{array}{c}9.75 \\
(0.75)\end{array}$ & $\begin{array}{l}13.66 \\
(3.11)\end{array}$ & $\begin{array}{l}11.66 \\
(0.88)\end{array}$ & $\begin{array}{c}13.0 \\
(1.86)\end{array}$ & $\begin{array}{l}24.23 \\
(0.72)\end{array}$ & $\begin{array}{c}33.6 \\
(7.02)\end{array}$ & $\begin{array}{l}26.11 \\
(1.53)\end{array}$ & $\begin{array}{l}35.33 \\
(5.24)\end{array}$ & $\begin{array}{l}12.29 \\
(1.66)\end{array}$ & $\begin{array}{c}8.55 \\
(1.23)\end{array}$ & $\begin{array}{l}12.77 \\
(1.09)\end{array}$ & $\begin{array}{c}10.7 \\
(1.41)\end{array}$ & $\begin{array}{l}29.41 \\
(3.68)\end{array}$ & $\begin{array}{l}23.47 \\
(1.15)\end{array}$ & $\begin{array}{l}32.18 \\
(3.02)\end{array}$ & $\begin{array}{l}23.08 \\
(0.94)\end{array}$ \\
\hline & $M L$ & $\begin{array}{l}10.27 \\
(0.75)\end{array}$ & $\begin{array}{l}12.56 \\
(1.74)\end{array}$ & $\begin{array}{l}12.98 \\
(0.85)\end{array}$ & $\begin{array}{l}13.25 \\
(0.95)\end{array}$ & $\begin{array}{c}22.1 \\
(1.21)\end{array}$ & $\begin{array}{l}30.49 \\
(4.32)\end{array}$ & $\begin{array}{l}21.93 \\
(1.45)\end{array}$ & $\begin{array}{c}38.13 \\
(5.53)\end{array}$ & $\begin{array}{l}12.07 \\
(0.99)\end{array}$ & $\begin{array}{c}8.83 \\
(1.18)\end{array}$ & $\begin{array}{l}13.42 \\
(0.66)\end{array}$ & $\begin{array}{l}12.27 \\
(1.47)\end{array}$ & $\begin{array}{l}27.49 \\
(2.42)\end{array}$ & $\begin{array}{l}19.67 \\
(1.49)\end{array}$ & $\begin{array}{l}32.24 \\
(3.18)\end{array}$ & $\begin{array}{l}17.44 \\
(0.82)\end{array}$ \\
\hline \multirow[t]{2}{*}{$\begin{array}{l}\text { Sway Temporal } \\
\left(\mathrm{mm}^{2} \cdot \mathrm{s}^{-1}\right)\end{array}$} & & $\begin{array}{l}13.09 \\
(1.06)\end{array}$ & $\begin{array}{l}21.81 \\
(5.84)\end{array}$ & $\begin{array}{l}19.84 \\
(1.63)\end{array}$ & $\begin{array}{l}25.25 \\
(4.78)\end{array}$ & $\begin{array}{c}106.01 \\
(8.0)\end{array}$ & $\begin{array}{l}190.49 \\
(44.91)\end{array}$ & $\begin{array}{c}102.99 \\
(6.17)\end{array}$ & $\begin{array}{l}166.99 \\
(20.19)\end{array}$ & $\begin{array}{l}19.23 \\
(3.12)\end{array}$ & $\begin{array}{c}9.3 \\
(0.76)\end{array}$ & $\begin{array}{l}24.88 \\
(2.75)\end{array}$ & $\begin{array}{l}14.59 \\
(1.13)\end{array}$ & $\begin{array}{l}153.29 \\
(24.11)\end{array}$ & $\begin{array}{c}97.86 \\
(13.29)\end{array}$ & $\begin{array}{l}144.87 \\
(86.0)\end{array}$ & $\begin{array}{l}82.57 \\
(5.62)\end{array}$ \\
\hline & $R D$ & $\begin{array}{c}0.52 \\
(0.02)\end{array}$ & $\begin{array}{c}0.52 \\
(0.03)\end{array}$ & $\begin{array}{c}0.58 \\
(0.03) \dagger\end{array}$ & $\begin{array}{c}0.59 \\
(0.04) \dagger\end{array}$ & $\begin{array}{c}0.91 \\
(0.87)\end{array}$ & $\begin{array}{c}0.87 \\
(0.02)\end{array}$ & $\begin{array}{c}0.92 \\
(0.03)\end{array}$ & $\begin{array}{c}0.94 \\
(0.03)\end{array}$ & $\begin{array}{c}0.51 \\
(0.02)\end{array}$ & $\begin{array}{c}0.54 \\
(0.04)\end{array}$ & $\begin{array}{c}058 \\
(0.03)\end{array}$ & $\begin{array}{c}0.59 \\
(0.04)\end{array}$ & $\begin{array}{c}0.89 \\
(0.03)\end{array}$ & $\begin{array}{c}0.92 \\
(0.05)\end{array}$ & $\begin{array}{c}0.91 \\
(0.02)\end{array}$ & $\begin{array}{c}0.96 \\
(0.04)\end{array}$ \\
\hline \multirow[t]{2}{*}{$\begin{array}{c}\text { Mean } \\
\text { Frequency }(\mathrm{Hz})\end{array}$} & $A P$ & $\begin{array}{c}0.81 \\
(0.03)\end{array}$ & $\begin{array}{c}0.87 \\
(0.05)\end{array}$ & $\begin{array}{c}1.09 \\
(0.04)\end{array}$ & $\begin{array}{c}1.14 \\
(0.08)\end{array}$ & $\begin{array}{c}2.17 \\
(0.09)\end{array}$ & $\begin{array}{c}2.58 \\
(0.11)\end{array}$ & $\begin{array}{c}2.18 \\
(0.08)\end{array}$ & $\begin{array}{c}2.59 \\
(0.12)\end{array}$ & $\begin{array}{c}0.87 \\
(0.03)\end{array}$ & $\begin{array}{c}0.75 \\
(0.03)\end{array}$ & $\begin{array}{c}1.14 \\
(0.05)\end{array}$ & $\begin{array}{c}1.01 \\
(0.07)\end{array}$ & $\begin{array}{c}2.48 \\
(0.08)\end{array}$ & $\begin{array}{c}1.93 \\
(0.13)\end{array}$ & $\begin{array}{c}2.44 \\
(0.08)\end{array}$ & $\begin{array}{c}2.07 \\
(0.11)\end{array}$ \\
\hline & $M L$ & $\begin{array}{c}0.92 \\
(0.03)\end{array}$ & $\begin{array}{c}1.01 \\
(0.05)\end{array}$ & $\begin{array}{c}0.99 \\
(0.04)\end{array}$ & $\begin{array}{c}1.03 \\
(0.06)\end{array}$ & $\begin{array}{c}2.26 \\
(0.08)\end{array}$ & $\begin{array}{c}2.07 \\
(0.05)\end{array}$ & $\begin{array}{c}2.2 \\
(0.07)\end{array}$ & $\begin{array}{l}2.31 \\
(0.1)\end{array}$ & $\begin{array}{c}0.97 \\
(0.03)\end{array}$ & $\begin{array}{c}0.91 \\
(0.04)\end{array}$ & $\begin{array}{c}1.03 \\
(0.04)\end{array}$ & $\begin{array}{c}0.96 \\
(0.05)\end{array}$ & $\begin{array}{c}2.1 \\
(0.05)\end{array}$ & $\begin{array}{c}2.41 \\
(0.12)\end{array}$ & $\begin{array}{c}2.22 \\
(0.06)\end{array}$ & $\begin{array}{c}2.29 \\
(0.11)\end{array}$ \\
\hline Fractal PD & & $\begin{array}{c}1.63 \\
(0.02)\end{array}$ & $\begin{array}{c}1.61 \\
(0.02)\end{array}$ & $\begin{array}{c}1.63 \\
(0.02)\end{array}$ & $\begin{array}{c}1.63 \\
(0.01)\end{array}$ & $\begin{array}{c}1.81 \\
(0.02)\end{array}$ & $\begin{array}{c}1.77 \\
(0.02)\end{array}$ & $\begin{array}{c}1.81 \\
(0.02)\end{array}$ & $\begin{array}{c}1.73 \\
(0.03)\end{array}$ & $\begin{array}{c}1.62 \\
(0.01)\end{array}$ & $\begin{array}{c}1.63 \\
(0.02)\end{array}$ & $\begin{array}{c}1.64 \\
(0.01)\end{array}$ & $\begin{array}{c}1.62 \\
(0.03)\end{array}$ & $\begin{array}{c}1.79 \\
(0.01)\end{array}$ & $\begin{array}{c}1.81 \\
(0.02)\end{array}$ & $\begin{array}{c}1.75 \\
(0.02)\end{array}$ & $\begin{array}{c}1.84 \\
(0.02)\end{array}$ \\
\hline Fractal CC & & $\begin{array}{c}1.59 \\
(0.01)\end{array}$ & $\begin{array}{c}1.59 \\
(0.01)\end{array}$ & $\begin{array}{c}1.64 \\
(0.01)\end{array}$ & $\begin{array}{c}1.64 \\
(0.02)\end{array}$ & $\begin{array}{c}1.87 \\
(0.02) \dagger\end{array}$ & $\begin{array}{c}1.85 \\
(0.01) \dagger\end{array}$ & $\begin{array}{c}1.87 \\
(0.01)\end{array}$ & $\begin{array}{c}1.88 \\
(0.01)\end{array}$ & $\begin{array}{c}1.59 \\
(0.01)\end{array}$ & $\begin{array}{c}1.57 \\
(0.01)\end{array}$ & $\begin{array}{c}1.65 \\
(0.01)\end{array}$ & $\begin{array}{c}1.62 \\
(0.02)\end{array}$ & $\begin{array}{l}1.87 \\
(0.01)\end{array}$ & $\begin{array}{c}1.85 \\
(0.02)\end{array}$ & $\begin{array}{l}1.88 \\
(0.01)\end{array}$ & $\begin{array}{c}1.87 \\
(0.02)\end{array}$ \\
\hline Fractal CE & & $\begin{array}{c}1.58 \\
(0.01)\end{array}$ & $\begin{array}{c}1.58 \\
(0.02)\end{array}$ & $\begin{array}{c}1.61 \\
(0.01)\end{array}$ & $\begin{array}{c}1.61 \\
(0.02)\end{array}$ & $\begin{array}{c}1.72 \\
(0.01)\end{array}$ & $\begin{array}{c}1.7 \\
(0.01)\end{array}$ & $\begin{array}{c}1.72 \\
(0.01)\end{array}$ & $\begin{array}{c}1.71 \\
(0.01)\end{array}$ & $\begin{array}{c}1.57 \\
(0.01)\end{array}$ & $\begin{array}{c}1.59 \\
(0.02)\end{array}$ & $\begin{array}{c}1.61 \\
(0.01)\end{array}$ & $\begin{array}{c}1.61 \\
(0.02)\end{array}$ & $\begin{array}{c}1.71 \\
(0.01)\end{array}$ & $\begin{array}{c}1.72 \\
(0.02)\end{array}$ & $\begin{array}{c}1.71 \\
(0.01)\end{array}$ & $\begin{array}{c}1.73 \\
(0.02)\end{array}$ \\
\hline
\end{tabular}

Data are expressed as mean (SEM). BEO= Bilateral Eyes Open; BEC=Bilateral Eyes Closed; UREO=Unilateral Right Eyes Open; ULEO=Unilateral Left Eyes Open; NAG= Non Arthropatic Group; HAG= Haemophilic Artropathy Group; $C G=$ Control Group; HG= Haemophilic Group. * Indicate a Haemophilia vs. Nonhaemophilia classifier feature. † Indicate an Arthropathy vs. Non-Arthropathy classifier feature. 
Table 2s. Descriptive statistics of the frequency domain variables.

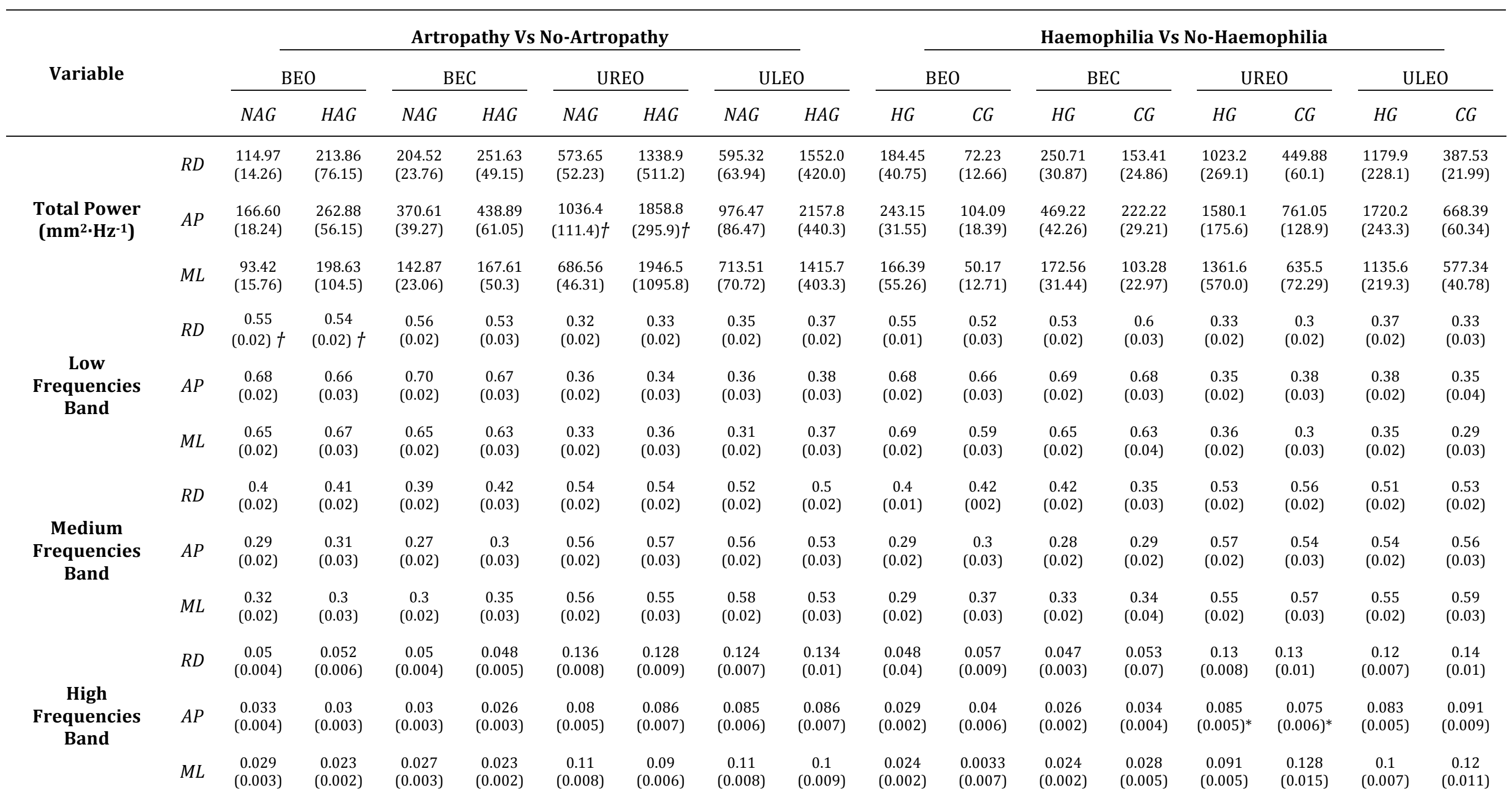




\begin{tabular}{|c|c|c|c|c|c|c|c|c|c|c|c|c|c|c|c|c|c|}
\hline & $R D$ & $\begin{array}{c}0.5 \\
(0.02) \dagger\end{array}$ & $\begin{array}{c}0.48 \\
(0.01) \dagger\end{array}$ & $\begin{array}{c}0.47 \\
(0.02)\end{array}$ & $\begin{array}{c}0.52 \\
(0.03)\end{array}$ & $\begin{array}{c}0.77 \\
(0.03)\end{array}$ & $\begin{array}{c}0.78 \\
(0.04)\end{array}$ & $\begin{array}{c}0.71 \\
(0.03)\end{array}$ & $\begin{array}{c}0.74 \\
(0.04)\end{array}$ & $\begin{array}{c}0.48 \\
(0.01)\end{array}$ & $\begin{array}{c}0.52 \\
(0.04)\end{array}$ & $\begin{array}{c}0.5 \\
(0.02)\end{array}$ & $\begin{array}{c}0.45 \\
(0.03)\end{array}$ & $\begin{array}{c}0.78 \\
(0.03)\end{array}$ & $\begin{array}{c}0.76 \\
(0.03)\end{array}$ & $\begin{array}{c}0.72 \\
(0.02)\end{array}$ & $\begin{array}{c}0.74 \\
(0.04)\end{array}$ \\
\hline \multirow[t]{3}{*}{$\begin{array}{c}\text { Median } \\
\text { Frequency }(\mathrm{Hz})\end{array}$} & $A P$ & $\begin{array}{c}0.37 \\
(0.02)\end{array}$ & $\begin{array}{c}0.39 \\
(0.02)\end{array}$ & $\begin{array}{c}0.36 \\
(0.01)\end{array}$ & $\begin{array}{c}0.37 \\
(0.03)\end{array}$ & $\begin{array}{l}0.67 \\
(0.03)\end{array}$ & $\begin{array}{c}0.72 \\
(0.04)\end{array}$ & $\begin{array}{c}0.66 \\
(0.03)\end{array}$ & $\begin{array}{c}0.67 \\
(0.04)\end{array}$ & $\begin{array}{c}0.38 \\
(0.01)\end{array}$ & $\begin{array}{c}0.38 \\
(0.03)\end{array}$ & $\begin{array}{c}0.37 \\
(0.02)\end{array}$ & $\begin{array}{c}0.35 \\
(0.02)\end{array}$ & $\begin{array}{c}0.7 \\
(0.03)^{*}\end{array}$ & $\begin{array}{c}0.65 \\
(0.04)^{*}\end{array}$ & $\begin{array}{c}0.66 \\
(0.03)\end{array}$ & $\begin{array}{c}0.68 \\
(0.04)\end{array}$ \\
\hline & $M L$ & $\begin{array}{c}0.42 \\
(0.02)\end{array}$ & $\begin{array}{c}0.41 \\
(0.03)\end{array}$ & $\begin{array}{c}0.43 \\
(0.02)\end{array}$ & $\begin{array}{c}0.44 \\
(0.02)\end{array}$ & $\begin{array}{c}0.71 \\
(0.02)\end{array}$ & $\begin{array}{c}0.67 \\
(0.03)\end{array}$ & $\begin{array}{c}0.7 \\
(0.03)\end{array}$ & $\begin{array}{c}0.69 \\
(0.04)\end{array}$ & $\begin{array}{c}0.4 \\
(0.02)\end{array}$ & $\begin{array}{c}0.44 \\
(0.03)\end{array}$ & $\begin{array}{c}0.43 \\
(0.02)\end{array}$ & $\begin{array}{c}0.44 \\
(0.04)\end{array}$ & $\begin{array}{c}0.67 \\
(0.02)\end{array}$ & $\begin{array}{c}0.75 \\
(0.04)\end{array}$ & $\begin{array}{c}0.69 \\
(0.03)\end{array}$ & $\begin{array}{c}0.71 \\
(0.04)\end{array}$ \\
\hline & $R D$ & $\begin{array}{c}2.34 \\
(0.13)\end{array}$ & $\begin{array}{l}2.25 \\
(0.1)\end{array}$ & $\begin{array}{c}2.14 \\
(0.11)\end{array}$ & $\begin{array}{c}2.07 \\
(0.11)\end{array}$ & $\begin{array}{c}3.47 \\
(0.12)\end{array}$ & $\begin{array}{c}3.31 \\
(0.11)\end{array}$ & $\begin{array}{c}3.31 \\
(0.12)\end{array}$ & $\begin{array}{c}3.31 \\
(0.12)\end{array}$ & $\begin{array}{c}2.2 \\
(0.09)\end{array}$ & $\begin{array}{c}2.55 \\
(0.21)\end{array}$ & $\begin{array}{c}2.03 \\
(0.08)\end{array}$ & $\begin{array}{c}2.31 \\
(0.18)\end{array}$ & $\begin{array}{l}3.34 \\
(0.1)\end{array}$ & $\begin{array}{c}3.58 \\
(0.17)\end{array}$ & $\begin{array}{l}3.23 \\
(0.1)\end{array}$ & $\begin{array}{c}3.51 \\
(0.18)\end{array}$ \\
\hline \multirow[t]{3}{*}{$\begin{array}{c}\text { 95\% Power } \\
\text { Frequency }(\mathrm{Hz})\end{array}$} & $A P$ & $\begin{array}{c}1.74 \\
(0.11)\end{array}$ & $\begin{array}{c}1.62 \\
(0.08)\end{array}$ & $\begin{array}{c}1.62 \\
(0.07) \dagger\end{array}$ & $\begin{array}{c}1.51 \\
(0.07) \dagger\end{array}$ & $\begin{array}{l}2.56 \\
(0.08)\end{array}$ & $\begin{array}{c}2.53 \\
(0.09)\end{array}$ & $\begin{array}{c}2.56 \\
(0.08)\end{array}$ & $\begin{array}{c}2.42 \\
(0.08)\end{array}$ & $\begin{array}{c}1.59 \\
(0.08)\end{array}$ & $\begin{array}{l}1.95 \\
(0.15)\end{array}$ & $\begin{array}{c}1.5 \\
(0.05)\end{array}$ & $\begin{array}{l}1.77 \\
(0.12)\end{array}$ & $\begin{array}{c}2.53 \\
(0.07)\end{array}$ & $\begin{array}{c}2.59 \\
(0.14)\end{array}$ & $\begin{array}{l}2.47 \\
(0.07)\end{array}$ & $\begin{array}{c}2.59 \\
(0.12)\end{array}$ \\
\hline & $M L$ & $\begin{array}{l}1.79 \\
(0.14)\end{array}$ & $\begin{array}{c}1.62 \\
(0.13)\end{array}$ & $\begin{array}{l}1.63 \\
(011)\end{array}$ & $\begin{array}{l}1.57 \\
(0.1)\end{array}$ & $\begin{array}{l}2.76 \\
(0.09)\end{array}$ & $\begin{array}{c}2.53 \\
(0.08)\end{array}$ & $\begin{array}{l}2.65 \\
(0.08)\end{array}$ & $\begin{array}{c}2.51 \\
(0.09)\end{array}$ & $\begin{array}{c}1.68 \\
(0.13)\end{array}$ & $\begin{array}{c}1.84 \\
(0.16)\end{array}$ & $\begin{array}{l}1.63 \\
(0.1)\end{array}$ & $\begin{array}{c}1.54 \\
(0.12)\end{array}$ & $\begin{array}{c}2.55 \\
(0.06)\end{array}$ & $\begin{array}{c}2.98 \\
(0.16)\end{array}$ & $\begin{array}{c}2.52 \\
(0.06)\end{array}$ & $\begin{array}{c}2.77 \\
(0.12)\end{array}$ \\
\hline & $R D$ & $\begin{array}{c}1.01 \\
(0.03) \dagger\end{array}$ & $\begin{array}{c}1.01 \\
(0.02) t\end{array}$ & $\begin{array}{c}0.99 \\
(0.03)\end{array}$ & $\begin{array}{c}0.1 \\
(0.04)\end{array}$ & $\begin{array}{c}1.45 \\
(0.03)\end{array}$ & $\begin{array}{c}1.42 \\
(0.04)\end{array}$ & $\begin{array}{c}1.4 \\
(0.03)\end{array}$ & $\begin{array}{c}1.43 \\
(0.04)\end{array}$ & $\begin{array}{c}0.99 \\
(0.02)\end{array}$ & $\begin{array}{c}1.05 \\
(0.04)\end{array}$ & $\begin{array}{c}0.99 \\
(0.03)\end{array}$ & $\begin{array}{c}1.0 \\
(0.04)\end{array}$ & $\begin{array}{c}1.44 \\
(0.03)\end{array}$ & $\begin{array}{l}1.46 \\
(0.04)\end{array}$ & $\begin{array}{c}1.38 \\
(0.03)\end{array}$ & $\begin{array}{c}1.47 \\
(0.05)\end{array}$ \\
\hline \multirow[t]{3}{*}{$\begin{array}{c}\text { Centroidal } \\
\text { Frequency }(\mathrm{Hz})\end{array}$} & $A P$ & $\begin{array}{c}0.85 \\
(0.03)\end{array}$ & $\begin{array}{c}0.83 \\
(0.03)\end{array}$ & $\begin{array}{c}0.81 \\
(0.02)\end{array}$ & $\begin{array}{c}0.8 \\
(0.03)\end{array}$ & $\begin{array}{c}1.2 \\
(0.03)\end{array}$ & $\begin{array}{c}1.24 \\
(0.03)\end{array}$ & $\begin{array}{c}1.21 \\
(0.08)\end{array}$ & $\begin{array}{c}1.21 \\
(0.04)\end{array}$ & $\begin{array}{c}0.82 \\
(0.02)\end{array}$ & $\begin{array}{c}0.9 \\
(0.04)\end{array}$ & $\begin{array}{c}0.79 \\
(0.02)\end{array}$ & $\begin{array}{c}0.85 \\
(0.03)\end{array}$ & $\begin{array}{c}1.23 \\
(0.03)\end{array}$ & $\begin{array}{l}1.18 \\
(004)\end{array}$ & $\begin{array}{c}1.19 \\
(0.03)\end{array}$ & $\begin{array}{c}1.25 \\
(0.05)\end{array}$ \\
\hline & $M L$ & $\begin{array}{c}0.83 \\
(0.02)\end{array}$ & $\begin{array}{c}0.79 \\
(0.03)\end{array}$ & $\begin{array}{c}0.81 \\
(0.03)\end{array}$ & $\begin{array}{c}0.89 \\
(0.03)\end{array}$ & $\begin{array}{c}1.29 \\
(0.03)\end{array}$ & $\begin{array}{c}1.21 \\
(0.03)\end{array}$ & $\begin{array}{c}1.29 \\
(0.03)\end{array}$ & $\begin{array}{c}1.27 \\
(0.04)\end{array}$ & $\begin{array}{c}0.8 \\
(0.02)\end{array}$ & $\begin{array}{c}0.86 \\
(0.04)\end{array}$ & $\begin{array}{c}0.8 \\
(0.02)\end{array}$ & $\begin{array}{c}0.82 \\
(0.04)\end{array}$ & $\begin{array}{c}1.22 \\
(0.02)\end{array}$ & $\begin{array}{c}1.38 \\
(0.06)\end{array}$ & $\begin{array}{c}1.26 \\
(0.03)\end{array}$ & $\begin{array}{c}1.34 \\
(0.05)\end{array}$ \\
\hline & $R D$ & $\begin{array}{c}0.67 \\
(0.006)\end{array}$ & $\begin{array}{c}0.67 \\
(0.007)\end{array}$ & $\begin{array}{c}0.67 \\
(0.006)\end{array}$ & $\begin{array}{c}0.65 \\
(0.007)\end{array}$ & $\begin{array}{c}0.65 \\
(0.005)\end{array}$ & $\begin{array}{c}0.64 \\
(0.009)\end{array}$ & $\begin{array}{c}0.65 \\
(0.005)\end{array}$ & $\begin{array}{c}0.65 \\
(0.007)\end{array}$ & $\begin{array}{c}0.67 \\
(0.005)\end{array}$ & $\begin{array}{c}0.67 \\
(0.01)\end{array}$ & $\begin{array}{c}0.65 \\
(0.05)\end{array}$ & $\begin{array}{c}0.68 \\
(0.009)\end{array}$ & $\begin{array}{c}0.64 \\
(0.006)\end{array}$ & $\begin{array}{c}0.65 \\
(0.007)\end{array}$ & $\begin{array}{c}0.65 \\
(0.005)\end{array}$ & $\begin{array}{c}0.65 \\
(0.008)\end{array}$ \\
\hline \multirow[t]{2}{*}{$\begin{array}{l}\text { Frequency } \\
\text { Dispersion }\end{array}$} & $A P$ & $\begin{array}{c}0.68 \\
(0.006)\end{array}$ & $\begin{array}{c}0.66 \\
(0.01)\end{array}$ & $\begin{array}{c}0.67 \\
(0.007)\end{array}$ & $\begin{array}{c}0.66 \\
(0.009)\end{array}$ & $\begin{array}{c}0.63 \\
(0.007)\end{array}$ & $\begin{array}{c}0.61 \\
(0.011)\end{array}$ & $\begin{array}{c}0.63 \\
(0.008)\end{array}$ & $\begin{array}{c}0.63 \\
(0.01)\end{array}$ & $\begin{array}{c}0.67 \\
(0.007)\end{array}$ & $\begin{array}{c}0.69 \\
(0.009)\end{array}$ & $\begin{array}{c}0.66 \\
(0.006)\end{array}$ & $\begin{array}{c}0.68 \\
(0.01)\end{array}$ & $\begin{array}{c}0.62 \\
(0.007)\end{array}$ & $\begin{array}{c}0.64 \\
(0.011)\end{array}$ & $\begin{array}{c}0.63 \\
(0.007)\end{array}$ & $\begin{array}{c}0.63 \\
(0.013)\end{array}$ \\
\hline & $M L$ & $\begin{array}{c}0.65 \\
(0.007)\end{array}$ & $\begin{array}{c}0.66 \\
(0.013)\end{array}$ & $\begin{array}{c}0.64 \\
(0.008)\end{array}$ & $\begin{array}{c}0.64 \\
(0.009)\end{array}$ & $\begin{array}{c}0.62 \\
(0.006)\end{array}$ & $\begin{array}{c}0.62 \\
(0.008)\end{array}$ & $\begin{array}{c}0.62 \\
(0.007)\end{array}$ & $\begin{array}{c}0.61 \\
(0.01)\end{array}$ & $\begin{array}{c}0.66 \\
(0.008)\end{array}$ & $\begin{array}{c}0.65 \\
(0.01)\end{array}$ & $\begin{array}{c}0.64 \\
(0.007)\end{array}$ & $\begin{array}{c}0.64 \\
(0.012)\end{array}$ & $\begin{array}{c}0.62 \\
(0.006)\end{array}$ & $\begin{array}{c}0.62 \\
(0.01)\end{array}$ & $\begin{array}{c}0.61 \\
(0.007)\end{array}$ & $\begin{array}{c}0.62 \\
(0.008)\end{array}$ \\
\hline
\end{tabular}

Data are expressed as mean (SEM). BEO= Bilateral Eyes Open; BEC= Bilateral Eyes Closed; UREO=Unilateral Right Eyes Open; ULEO=Unilateral Left Eyes

Open; NAG= Non Arthropatic Group; HAG= Haemophilic Artropathy Group; $C G=$ Control Group; HG= Haemophilic Group. * Indicate a Haemophilia vs. Non-

haemophilia classifier feature. † Indicate an Arthropathy vs. Non-Arthropathy classifier feature. 
Table 3s. Descriptive statistics of the non-linear analysis variables.

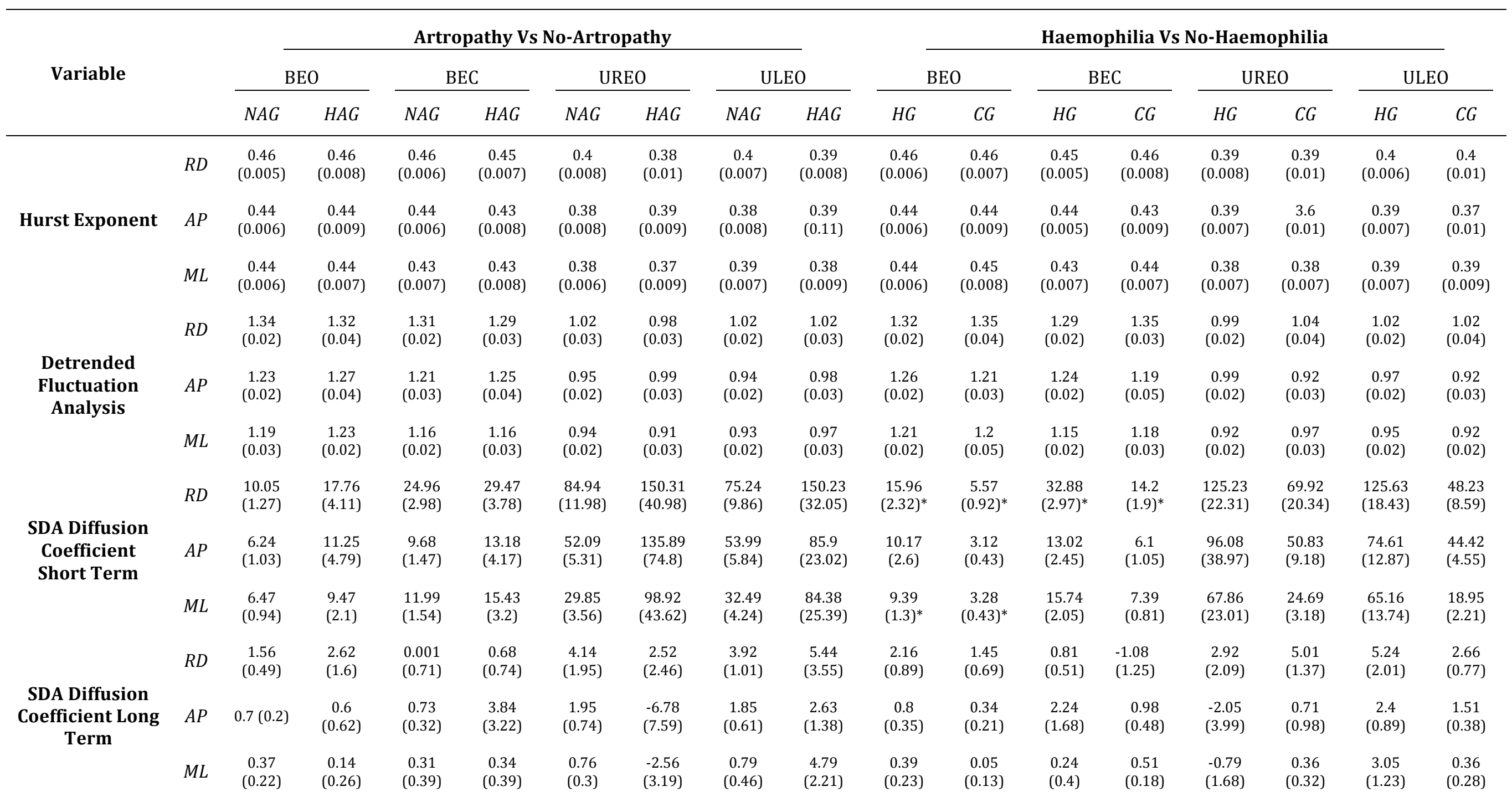




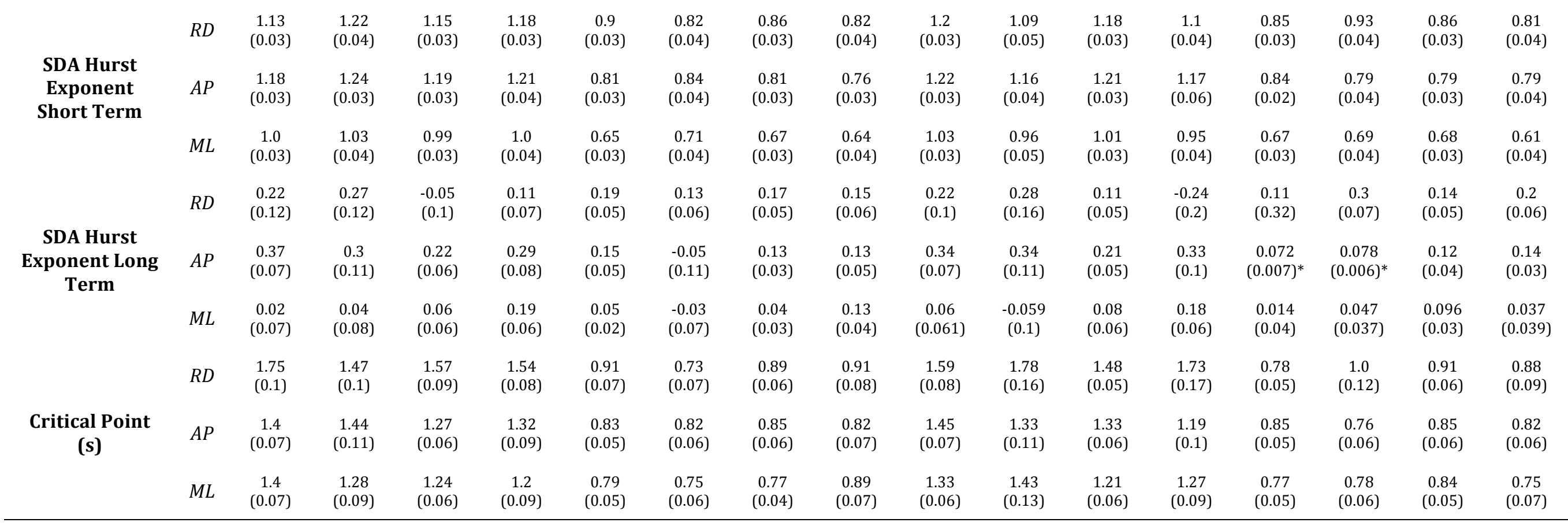

Data are expressed as mean (SEM). BEO= Bilateral Eyes Open; BEC=Bilateral Eyes Closed; UREO=Unilateral Right Eyes Open; ULEO= Unilateral Left Eyes

Open; NAG= Non Arthropatic Group; HAG= Haemophilic Artropathy Group; CG= Control Group; HG= Haemophilic Group. *Indicate a Haemophilia vs. Non-

haemophilia classifier feature. † Indicate an Arthropathy vs. Non-Arthropathy classifier feature. 